\title{
Penicyrones A and B, an epimeric pair of $\alpha$-pyrone-type polyketides produced by the marine-derived Penicillium sp.
}

\author{
Ying-Yue Bu, Hiroyuki Yamazaki, Ohgi Takahashi, Ryota Kirikoshi, Kazuyo Ukai and Michio Namikoshi
}

Two polyketides containing an $\alpha$-pyrone unit, named penicyrones A (1) and B (2), were isolated from a culture broth of the marine-derived Penicillium sp. TPU1271 together with nine known compounds: verrucosidin (3), fructigenine A (4), verrucofortine (5), cyclo-(L-Trp-L-Phe) (6), cyclopenol (7), cyclopenin (8), penipratynolene (9), aspterric acid (10) and viridicatol (11). The structures of 1 and 2 were elucidated by analyzing the spectroscopic data of 1,2 and their 0 -acetyl derivatives (1a and 2a). Compounds 1 and 2 were epimers of each other at the C-9 position. The absolute configurations of 1 and 2 were assigned on the basis of NOESY data for 1, 2, 1a and 2a, a conformational analysis and the identity of the biogenetic pathway with verrucosidin (3). The planar structure of penicyrones was found in the SciFinder as a compound in the commercial chemical libraries; however, the stereostructure and spectroscopic data were not available. Therefore, this is the first study on the isolation and structure elucidation, including the absolute configurations, of penicyrones A (1) and B (2) as fungal metabolites. Compound 3 exhibited growth inhibitory activity against Mycobacterium smegmatis at $40 \mu \mathrm{g}$ per disc (inhibition zone of $11 \mathrm{~mm}$ ). This is the first study to demonstrate that verrucosidin (3) exhibited anti-mycobacterial activity. The Journal of Antibiotics (2016) 69, 57-61; doi:10.1038/ja.2015.82; published online 5 August 2015

\section{INTRODUCTION}

Marine natural resources have continued to provide structurally and biologically novel compounds, some of which are promising leads for the development of new drugs. ${ }^{1-3}$ Marine microorganisms, especially marine-derived fungi, have been attractive and important sources of pharmacologically active secondary metabolites. ${ }^{4-6}$ Marine fungal metabolites, possessing unique structures and biological properties, are expected to become candidates for advanced medicines and biochemical reagents. ${ }^{4-6}$

In the course of our search for useful bioactive substances from marine microorganisms, the marine-derived Penicillium sp. TPU1271 was found to produce various types of secondary metabolites. HPLC separation from a culture broth of strain TPU1271 led to the isolation of an epimeric pair of polyketides containing $\alpha$-pyrone and the tetrahydrofuran rings, penicyrones A (1) and B (2) (Figure 1), as well as nine known compounds: verrucosidin (3), ${ }^{7-11}$ fructigenine A (4), ${ }^{12,13}$ verrucofortine (5), ${ }^{9,12}$ cyclo-(L-Trp-L-Phe) (6), ${ }^{14,15}$ cyclopenol (7), ${ }^{9,16}$ cyclopenin (8), ${ }^{9,17}$ penipratynolene (9), ${ }^{18,19}$ aspterric acid $(\mathbf{1 0})^{20}$ and viridicatol $(\mathbf{1 1})^{16,21}$ (Figure 1). Although the planar structure of penicyrones was found in the SciFinder as a compound in commercial chemical libraries, the stereostructure, spectroscopic data and origin were not available. We described herein the isolation of penicyrones A (1) and B (2) as secondary metabolites from the marine-derived Penicillium sp., structures including the absolute configurations of $\mathbf{1}$ and $\mathbf{2}$ and the anti-mycobacterial activity of verrucosidin (3). This is the first study to demonstrate that verrucosidin (3) exhibited inhibitory activity against Mycobacterium smegmatis.

\section{RESULTS AND DISCUSSION}

\section{Structure elucidation}

Compounds 3-11 were identified as verrucosidin, fructigenine A, verrucofortine, cyclo-(L-Trp-L-Phe), cyclopenol, cyclopenin, penipratynolene, aspterric acid and viridicatol, respectively (Figure 1), by comparing their spectroscopic data with the reported values. ${ }^{7-21}$

Penicyrones A (1) and B (2) were first obtained as a mixture by HPLC (octadecylsilyl (ODS)) with $\mathrm{CH}_{3} \mathrm{OH}-\mathrm{H}_{2} \mathrm{O}$ (1:1). The mixture showed a clear ${ }^{1} \mathrm{H}$ NMR spectrum; however, two sets of signals were detected for several carbons in the ${ }^{13} \mathrm{C}$ NMR spectrum. The isolation of $\mathbf{1}$ and $\mathbf{2}$ was achieved by repeated HPLC (ODS) with $\mathrm{CH}_{3} \mathrm{OH}-\mathrm{H}_{2} \mathrm{O}(2: 3)$.

Compound 1 was isolated as a colorless oil. The MW and formula of 1,434 and $\mathrm{C}_{24} \mathrm{H}_{34} \mathrm{O}_{7}$, respectively, were determined from the HRFABMS (high-resolution fast atom bombardment mass spectra) and NMR data. ${ }^{1} \mathrm{H}$ and ${ }^{13} \mathrm{C}$ NMR spectra showed 32 protons and 24 carbons (Table 1), which were classified into eight methyl, one oxygenated methyl, three $\mathrm{sp}^{3}$ oxygenated methine, three $\mathrm{sp}^{3}$ oxygenated quaternary, two $\mathrm{sp}^{2}$ methine, four $\mathrm{sp}^{2}$ quaternary, two $\mathrm{sp}^{2}$ oxygenated quaternary and one carbonyl carbons by an analysis of HMQC and DEPT spectra. The ${ }^{1} \mathrm{H}$ NMR spectrum of 1 resembled 


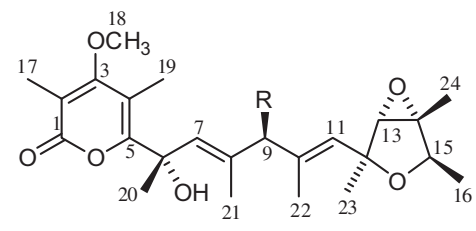

penicyrone $\mathrm{A}(\mathbf{1}): \mathrm{R}=\mathrm{OH}$

9-O-acetyl-penicyrone A (1a): R = OAc<smiles>[R]C(/C(C)=C/[C@@](C)(O)c1oc(=O)c(C)c(OC)c1C)/C(C)=C/[C@@]1(C)O[C@H](C)[C@@]2(C)O[C@H]12</smiles>

penicyrone $\mathrm{B}(\mathbf{2}): \mathrm{R}=\mathrm{OH}$

9-O-acetyl-penicyrone B (2a): R = OAc<smiles>COc1c(C)c([C@@]2(C)O[C@@H]2/C(C)=C/C(C)=C/[C@@]2(C)OC(C)[C@@]3(C)O[C@@H]23)oc(=O)c1C</smiles>

verrucosidin (3)<smiles>[R]c1cccc(C2OC2C(=O)Nc2ccccc2C(=O)O)c1</smiles>

cyclopenol (7): $\mathrm{R}=\mathrm{OH}$ cyclopenin $(8): \mathrm{R}=\mathrm{H}$<smiles>[R]C[C@H]1NC(=O)[C@@H]2C[C@@]3(C(C)(C)C=C)c4ccccc4N([Z10])[C@H]3N2C1=O</smiles>

fructigenine $A(4): R=P h$ verrucofortine (5): $\mathrm{R}=\mathrm{Pr}-\mathrm{i}$<smiles>O=C1N[C@H](Cc2c[nH]c3ccccc23)C(=O)N[C@@H]1Cc1ccccc1</smiles>

cyclo-(L-Trp-L-Phe) (6)

Figure 1 Structures of compounds $1-11$ produced by the marine-derived fungus Penicillium sp. TPU1271.

Table $1{ }^{13} \mathrm{C}(100 \mathrm{MHz})$ and ${ }^{1} \mathrm{H}(400 \mathrm{MHz})$ NMR data for penicyrones $A(1)$ and $B(2)$ in $C_{3} O D$

\begin{tabular}{|c|c|c|c|c|}
\hline \multirow[b]{2}{*}{ C no. } & \multicolumn{2}{|r|}{1} & \multicolumn{2}{|r|}{2} \\
\hline & $\delta_{C}$ & $\delta_{H}$, mult. $(\mathrm{J}$ in $\mathrm{Hz})$ & $\delta_{C}$ & $\delta_{H}$, mult. $(\mathrm{J}$ in $\mathrm{Hz})$ \\
\hline 1 & 167.7 & & 167.7 & \\
\hline 2 & 110.9 & & 110.9 & \\
\hline 3 & 171.9 & & 171.9 & \\
\hline 4 & 113.4 & & 113.3 & \\
\hline 5 & 162.8 & & 162.8 & \\
\hline 6 & 75.3 & & 75.3 & \\
\hline 7 & 133.8 & $5.88, \mathrm{t}(1.2)$ & 134.1 & $5.86, \mathrm{t}(1.2)$ \\
\hline 8 & 137.7 & & 137.8 & \\
\hline 9 & 82.6 & $4.23, \mathrm{~s}$ & 82.6 & $4.24, \mathrm{~s}$ \\
\hline 10 & 139.7 & & 139.8 & \\
\hline 11 & 130.3 & $5.70, \mathrm{t}(1.5)$ & 129.9 & $5.69, \mathrm{t}(1.2)$ \\
\hline 12 & 81.7 & & 81.7 & \\
\hline 13 & 68.9 & $3.55, \mathrm{~s}$ & 68.89 & $3.54, \mathrm{~s}$ \\
\hline 14 & 68.8 & & 68.86 & \\
\hline 15 & 78.4 & $4.03, \mathrm{q}(6.8)$ & 78.4 & 4.03, q (6.9) \\
\hline 16 & 19.4 & $1.14, \mathrm{~d}(6.8)$ & 19.4 & $1.13, \mathrm{~d}(6.9)$ \\
\hline 17 & 10.3 & $2.02, \mathrm{~s}$ & 10.3 & $2.02, \mathrm{~s}$ \\
\hline 18 & 61.3 & $3.85, \mathrm{~s}$ & 61.3 & $3.85, \mathrm{~s}$ \\
\hline 19 & 11.1 & $2.10, \mathrm{~s}$ & 11.1 & $2.09, \mathrm{~s}$ \\
\hline 20 & 27.9 & $1.63, \mathrm{~s}$ & 28.0 & $1.64, \mathrm{~s}$ \\
\hline 21 & 13.1 & 1.33, s (overlapped) & 13.1 & 1.33, br d (1.0) \\
\hline 22 & 14.4 & 1.70, br d (1.2) & 14.7 & $1.71, \mathrm{~d}(1.2)$ \\
\hline 23 & 22.1 & 1.33, s (overlapped) & 22.1 & $1.32, \mathrm{~s}$ \\
\hline 24 & 13.9 & $1.43, \mathrm{~s}$ & 13.8 & $1.42, \mathrm{~s}$ \\
\hline
\end{tabular}

that of verrucosidin (3), which suggested the presence of $\alpha$-pyrone and tetrahydrofuran rings in $1 .{ }^{1} \mathrm{H}-{ }^{1} \mathrm{H}$ COSY data for 1 revealed two partial structures of C-15-C-16 and C-7-C-11 with C-21 and C-22. The connections of the two partial structures with $\alpha$-pyrone and tetrahydrofuran rings were assigned by $\mathrm{HMBC}$ data for $\mathbf{1}$ (Figure 2). $\mathrm{HMBC}$ correlations were detected from $\mathrm{H}_{3}-20$ ( $\left.\delta 1.63\right)$ to $\mathrm{C}-5$ (162.8), C-6 (75.3) and C-7 (133.8), from H-11 (5.70) to C-12 (81.7) and C-13 (68.9) and from $\mathrm{H}_{3}-23$ (1.33) to $\mathrm{C}-11$ (130.3), C-12 and C-13. The NOESY correlations between H-7 ( $\delta 5.88) / \mathrm{H}-9(\delta 4.23), \mathrm{H}-7 / \mathrm{H}_{3}-20$ (1.63), $\mathrm{H}-11$ (5.70)/H-13 (3.55), $\mathrm{H}_{3}-21$ (1.33)/ $\mathrm{H}_{3}-22$ (1.70) and $\mathrm{H}_{3}-22 / \mathrm{H}_{3}-23$ (1.33) established the E-orientation of two double bonds at C-7 and C-10 (Figure 2). Thus, the planar structure of 1 was determined as shown in Figure 2.

HRFABMS and NMR data for compound 2 revealed that the MW and formula (434, $\mathrm{C}_{24} \mathrm{H}_{34} \mathrm{O}_{7}$ ) of 2 were the same as those of $\mathbf{1} .{ }^{1} \mathrm{H}$ and ${ }^{13} \mathrm{C}$ NMR data for $\mathbf{2}$ were very similar to those for $\mathbf{1}$ (Table 1 ). Moreover, the 2D NMR spectra $\left({ }^{1} \mathrm{H}-{ }^{1} \mathrm{H}\right.$ COSY, HMQC, HMBC and NOESY) of $\mathbf{2}$ showed the same correlations as those of $\mathbf{1}$. Therefore, the planar structure of $\mathbf{2}$ was elucidated to be the same as that of $\mathbf{1}$ (Figure 2).

This planar structure was found in the SciFinder as a commercially available reagent in chemical libraries for the screening of drug discovery. However, the origin, spectroscopic data and stereochemistry were not described. Consequently, this is the first study to isolate $\mathbf{1}$ and $\mathbf{2}$ as natural products from a fungal culture broth.

Absolute configurations of penicyrones A (1) and B (2) NOE correlations between H-11 (1, $\delta 5.70 ; 2, \delta 5.69) / \mathrm{H}-13$ (1, 3.55; 2 , 5.54), $\mathrm{H}-13 / \mathrm{H}-24(1,1.43 ; 2,1.42)$ and $\mathrm{H}-16(1,1.14 ; 2,1.13) / \mathrm{H}-24$ observed in the NOESY spectra of $\mathbf{1}$ and $\mathbf{2}$ suggested that the relative configurations of $\mathbf{1}$ and $\mathbf{2}$ were the same as that of $\mathbf{3}$. As compounds $\mathbf{1}$ $(+110.0), 2(+96.0)$ and $3(+70.0)$ showed similar specific rotations and were produced by the same fungal strain TPU1271 through the identical biogenetic pathway, the absolute configurations at the tetrahydrofuran ring (C-12-C-16) in $\mathbf{1}$ and $\mathbf{2}$ were assigned the same as those in 3. The absolute configuration of $\mathbf{3}$ was previously established by organic synthetic studies. ${ }^{22-24}$

Slight differences in ${ }^{13} \mathrm{C}$ chemical shifts were detected for the signals due to C-7, C-8 and C-22, which indicated that 1 and 2 were the 
epimers of each other at the C-9 position. As NOESY data for $\mathbf{1}$ and $\mathbf{2}$ could not distinguish the configuration at C-9, 9-O-acetyl derivatives (1a and $\mathbf{2 a}$ ) were prepared. The ${ }^{1} \mathrm{H}$ NMR spectra of $\mathbf{1 a}$ and $\mathbf{2 a}$ showed marked differences in the chemical shifts at H-9 (1a, $\delta 5.32$ and 2a, 5.30) and the acetyl methyl (1a, 2.05 and $\mathbf{2 a}, 2.02$ ). NOESY data for 1a showed the correlations between $\mathrm{H}_{3}-26$ ( $\left.\delta 2.05\right) / \mathrm{H}_{3}-21$ (1.39) and $\mathrm{H}_{3}-26 / \mathrm{H}_{3}-22$ (1.76), and a correlation between $\mathrm{H}_{3}-26(2.02) / \mathrm{H}_{3}-20$ (1.62) was observed in the NOESY spectrum of $2 \mathbf{a}$. Based on the NOESY correlations, the most stable conformers of $9 R$ and $9 S$ isomers for $\mathrm{O}$-acetyl derivatives were calculated by a Monte Carlo conformational analysis with an MMFF94 force field using Spartan'14. The stereostructures of the $9 R$ isomer (Figure 3a) and $9 S$ isomer (Figure $3 \mathrm{~b}$ ) agreed with the configurations of $\mathbf{1 a}$ and $\mathbf{2 a}$, respectively. The configurations at the C- 6 positions in $\mathbf{1}$ and $\mathbf{2}$ were assigned by the correlations between $\mathrm{H}-7$ and $\mathrm{H}_{3}-20$ in the NOESY spectra of $\mathbf{1}, \mathbf{2}$, 1a and $2 \mathbf{a}$.

Thus, the absolute configurations of $\mathbf{1}$ and $\mathbf{2}$ were elucidated as $(6 S, 9 R, 12 S, 13 S, 14 R, 15 R)$ and $(6 S, 9 S, 12 S, 13 S, 14 R, 15 R)$, respectively, as shown in Figure 1.

\section{Biological activity}

The anti-bacterial activities of compounds 1-11 against $M$. smegmatis NBRC 3207 were evaluated by the paper disc method. ${ }^{25,26}$ Verrucosidin (3) showed an inhibition zone of $11 \mathrm{~mm}$ at $40 \mu \mathrm{g}$ per disc. Compound 3 was initially isolated from Penicillium verrucosum var. cyclopium as a potent neurotoxin, ${ }^{7}$ and its inhibitory effects on GRP78 promoter expression has recently been reported. ${ }^{11}$ Consequently, this is the first study to demonstrate that verrucosidin (3) exhibited anti-mycobacterial activity. In spite of the structural similarities of 1-3, the two new compounds did not inhibit the growth of M. smegmatis.

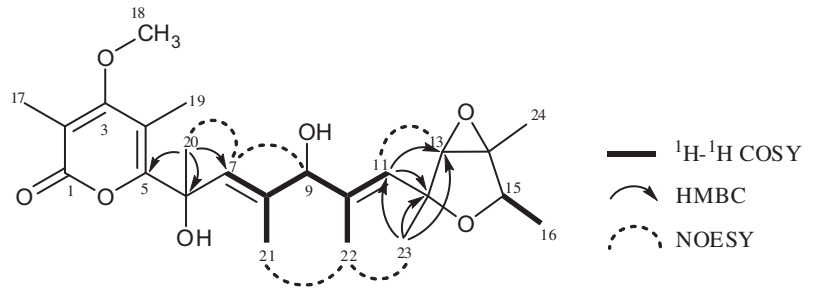

Figure $2{ }^{1} \mathrm{H}^{1} \mathrm{H}$ COSY, key $\mathrm{HMBC}$ and key NOESY correlations for penicyrones $A(\mathbf{1})$ and $B(2)$.

a

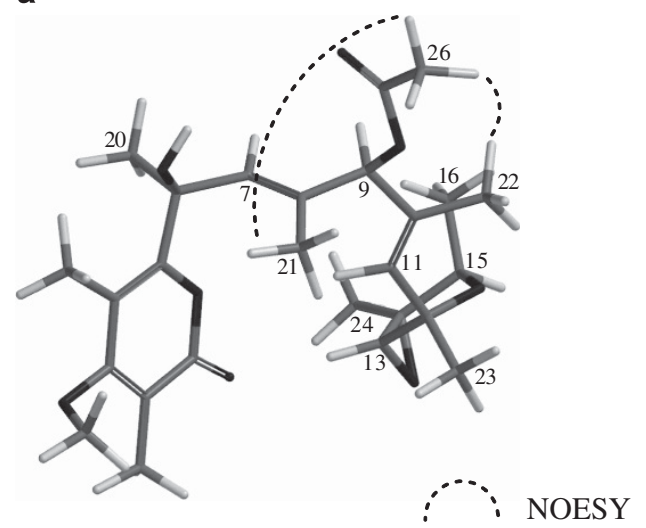

\section{MATERIALS AND METHODS}

\section{General experimental procedures}

FABMS was performed using a JMS-MS 700 mass spectrometer (JEOL, Tokyo, Japan). ${ }^{1} \mathrm{H}$ and ${ }^{13} \mathrm{C}$ NMR spectra were recorded on a JNM-AL-400 NMR spectrometer (JEOL) at $400 \mathrm{MHz}$ for ${ }^{1} \mathrm{H}$ and $100 \mathrm{MHz}$ for ${ }^{13} \mathrm{C}$ in $\mathrm{CD}_{3} \mathrm{OD}$ $\left(\delta_{\mathrm{H}} 3.31, \delta_{\mathrm{C}} 49.15\right)$. Optical rotations were measured with a JASCO P-2300 digital polarimeter (JASCO, Tokyo, Japan). UV spectra were obtained on a Hitachi U-3310 UV-Visible spectrophotometer (Hitachi, Tokyo, Japan) and IR spectra on a Perkin-Elmer Spectrum One Fourier transform infrared spectrometer (Perkin-Elmer, Waltham, MA, USA). CD spectra were measured with a spectrometer (J-720; JASCO). Secondary metabolites were analyzed by a LaChrom Elite HTA system (Hitachi). Preparative HPLC was conducted using a Toyosoda CCPU dual pump (Toyosoda Kogyo, Tokyo, Japan) with a Tosoh UV-8010 detector (Tosoh, Tokyo, Japan).

\section{Materials}

Potato dextrose agar, Middlebook 7H9 broth, polysorbate 80 and Middlebook OADC were purchased from BD (Franklin Lakes, NJ, USA). All other chemicals including organic solvents were purchased from Wako Pure Chemical Industries (Osaka, Japan).

\section{Isolation and identification of strain TPU1271}

The fungal strain TPU1271 was isolated from organic debris attached to a cultured oyster shell collected at a depth of $10 \mathrm{~m}$ in the Oshika Peninsula, Miyagi Prefecture, Japan, in June 2012. The debris was suspended in $25 \mathrm{ml}$ of sterilized seawater, and $200 \mu \mathrm{l}$ of the mixture was spread on an agar plate (potato dextrose agar, 90\% seawater) and incubated at $25^{\circ} \mathrm{C}$. Strain TPU1271 was identified by the sequence of its ITS1 rDNA (231 nucleotides). Twentynine known Penicillium species including P. polonicum, $P$. cordubense and P. crustosum showed $100 \%$ identity, and, therefore, strain TPU1271 was identified as a Penicillium sp. The following sequence was used in a BLAST search: 5'-AGGTGAACCTGCGGAAGGATCATTACCGAGTGAGGGCCCTTT GGGTCCAACCTCCCACCCGTGTTTATTTTACCTTGTTGCTTCGGCGGG CCCGCCTTTACTGGCCGCCGGGGGGCTCACGCCCCCGGGCCCGCGCC CGCCGAAGACACCCCCGAACTCTGTCTGAAGATTGAAGTCTGAGTGAA AATATAAATTATTTAAAACTTTCAACAACGGATCTCTTGGTTCCGG-3'.

\section{Fermentation}

Strain TPU1271, which was grown on the potato dextrose agar plate, was inoculated into a 100-ml Erlenmeyer flask containing $40 \mathrm{ml}$ of the seed medium $\left(2.0 \%\right.$ glucose, $0.5 \%$ polypeptone, $0.05 \% \mathrm{MgSO}_{4} \cdot 7 \mathrm{H}_{2} \mathrm{O}, 0.2 \%$ yeast extract, $0.1 \% \mathrm{KH}_{2} \mathrm{PO}_{4}, 0.1 \%$ agar in natural seawater; adjusted to $\mathrm{pH} 6.0$ before sterilization). The flask was shaken reciprocally for 3 days at $25^{\circ} \mathrm{C}$ to obtain the seed culture, which was then transferred to the production medium $(3.0 \%$ sucrose, 3.0\% soluble starch, $1.0 \%$ malt extract, $0.30 \%$ Ebios (Asahi Food and Healthcare, Tokyo, Japan), $0.50 \% \quad \mathrm{KH}_{2} \mathrm{PO}_{4}$ and $0.050 \% \mathrm{MgSO}_{4} \cdot 7 \mathrm{H}_{2} \mathrm{O}$ in

b

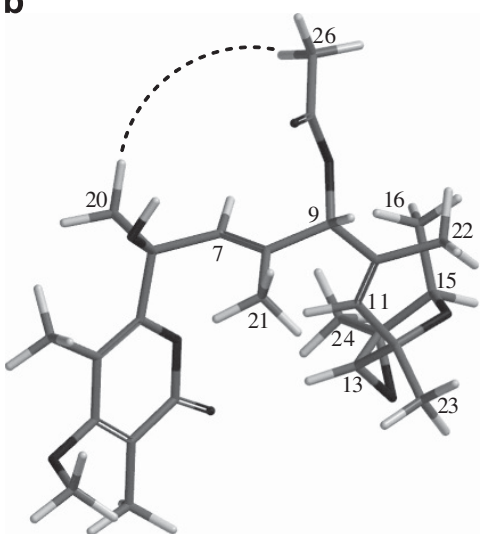

Figure 3 The calculated most stable conformers with key NOESY correlations for (a) 1 a and (b) 2a. A full color version of this figure is available at The Journal of Antibiotics journal online. 
natural seawater; adjusted to $\mathrm{pH} 6.0$ before sterilization). The production culture was carried out at room temperature for 21 days under static conditions.

\section{Extraction and isolation of compounds 1-11}

Acetone (3.0 l) was added to the culture broth (3.01) after 21 days and filtered. The filtrate was concentrated to remove acetone, and the aqueous residue was adsorbed on an ODS column. The column was eluted stepwise with 10, 30, 40, $50,60,70,80,90$ and $100 \% \mathrm{CH}_{3} \mathrm{OH}$ in $\mathrm{H}_{2} \mathrm{O}$ for separation into nine fractions. Fr. 5 (171.4 mg, $60 \% \mathrm{CH}_{3} \mathrm{OH}$ eluate) was separated by HPLC (column; PEGASIL ODS SP100 (Senshu Scientific, Tokyo, Japan), $10 \times 250 \mathrm{~mm}^{2}$; mobile phase, $50 \% \mathrm{CH}_{3} \mathrm{OH}$; detection, $\mathrm{UV}$ at $210 \mathrm{~nm}$; flow rate, $2.0 \mathrm{ml} \mathrm{min}^{-1}$ ) to give compounds $\mathbf{6}(2.1 \mathrm{mg}), \mathbf{8}(11.2 \mathrm{mg}), \mathbf{9}(2.4 \mathrm{mg})$ and $\mathbf{1 1}(5.5 \mathrm{mg})$, and a mixture of 1 and $2(54.7 \mathrm{mg})$. Compounds $1(5.5 \mathrm{mg})$ and $2(4.1 \mathrm{mg})$ were purified from a portion of the mixture by repeated HPLC (PEGASIL ODS SP100, 40\% $\left.\mathrm{CH}_{3} \mathrm{OH}, \mathrm{UV} 215 \mathrm{~nm}, 2.0 \mathrm{ml} \mathrm{min}{ }^{-1}, t_{\mathrm{R}}=\sim 180 \mathrm{~min}\right)$. Compounds $4(19.0 \mathrm{mg})$, $5(2.6 \mathrm{mg})$ and $\mathbf{1 0}(80.5 \mathrm{mg})$ were isolated from Fr. $7\left(161.0 \mathrm{mg}, 80 \% \mathrm{CH}_{3} \mathrm{OH}\right.$ eluate) by HPLC (PEGASIL ODS SP100, $70 \% \mathrm{CH}_{3} \mathrm{OH}, \mathrm{UV}$ at $210 \mathrm{~nm}$, $\left.2.0 \mathrm{ml} \mathrm{min}^{-1}\right)$. Compound $3(17.5 \mathrm{mg})$ was obtained by HPLC $\left(80 \% \mathrm{CH}_{3} \mathrm{OH}\right)$ from Fr. 8 (70.5 mg, 90\% $\mathrm{CH}_{3} \mathrm{OH}$ eluate). Fr. 3 (200.2 mg, 40\% $\mathrm{CH}_{3} \mathrm{OH}$ eluate) was separated by a Sephadex LH-20 column (GE Healthcare UK Ltd., Buckinghamshire, UK) with $30 \% \mathrm{CH}_{3} \mathrm{OH}$ to yield compound 7 (90.0 mg).

Penicyrone A (1): A colorless oil; $[\alpha]_{\mathrm{D}}^{20}+110\left(c 0.10, \mathrm{CH}_{3} \mathrm{OH}\right) ; \mathrm{IR}(\mathrm{KBr}) \nu_{\max }$ 3426, 2978, 2929, 2857, 1688, 1558, 1451, 1377, 1095, 1043 and $1012 \mathrm{~cm}^{-1}$; UV $\left(\mathrm{CH}_{3} \mathrm{OH}\right) \lambda_{\max }(\mathrm{nm})(\log \varepsilon) 306(3.40) ; \mathrm{CD}\left(\mathrm{CH}_{3} \mathrm{OH}\right) \lambda_{\text {extermum }}(\mathrm{nm})(\Delta \varepsilon) 298$ $(+12.9), 213(-40.9)$; HRFABMS $m / z 435.2389\left([\mathrm{M}+\mathrm{H}]^{+}\right.$; calcd for $\mathrm{C}_{24} \mathrm{H}_{35} \mathrm{O}_{7}$, 435.2383); ${ }^{1} \mathrm{H}$ and ${ }^{13} \mathrm{C}$ NMR $\left(\mathrm{CD}_{3} \mathrm{OD}\right)$ (see Table 1$)$.

Penicyrone B (2): A colorless oil; $[\alpha]_{\mathrm{D}}^{20}+96.0\left(c 0.10, \mathrm{CH}_{3} \mathrm{OH}\right)$; IR (KBr) $\nu_{\max }$ 3436, 2978, 2934, 2863,1683, 1558, 1451, 1380, 1092, 1048 and $1026 \mathrm{~cm}^{-1}$; UV $\left(\mathrm{CH}_{3} \mathrm{OH}\right) \lambda_{\max }(\mathrm{nm})(\log \varepsilon) 304(3.63) ; \mathrm{CD}\left(\mathrm{CH}_{3} \mathrm{OH}\right) \lambda_{\text {extermum }}(\mathrm{nm})(\Delta \varepsilon) 298$ $(+12.0), 213(-38.8)$; HRFABMS $m / z 435.2391\left([\mathrm{M}+\mathrm{H}]^{+}\right.$; calcd for $\mathrm{C}_{24} \mathrm{H}_{35} \mathrm{O}_{7}$, 435.2383); ${ }^{1} \mathrm{H}$ and ${ }^{13} \mathrm{C}$ NMR $\left(\mathrm{CD}_{3} \mathrm{OD}\right)$ (see Table 1$)$.

Verrucosidin (3): A pale yellow oil; $[\alpha]_{\mathrm{D}}^{22}+70.0$ (c 0.10, $\left.\mathrm{CH}_{3} \mathrm{OH}\right)$; $\mathrm{CD}$ $\left(\mathrm{CH}_{3} \mathrm{OH}\right) \lambda_{\text {extermum }}(\mathrm{nm})(\Delta \varepsilon) 291(+1.48), 241(+8.78)$; EIMS $\mathrm{m} / z 416[\mathrm{M}]^{+}$; ${ }^{1} \mathrm{H}$ NMR $\left(\mathrm{CD}_{3} \mathrm{OD}\right): \delta 5.83(1 \mathrm{H}, \mathrm{s}), 5.44(1 \mathrm{H}, \mathrm{ts}), 4.10(1 \mathrm{H}, \mathrm{q}, J=6.8 \mathrm{~Hz}), 3.80$ $(3 \mathrm{H}, \mathrm{s}), 3.46(1 \mathrm{H}, \mathrm{s}), 3.40(1 \mathrm{H}, \mathrm{s}), 2.02(3 \mathrm{H}, \mathrm{s}), 2.01(3 \mathrm{H}, \mathrm{s}), 1.93(3 \mathrm{H}, \mathrm{brs})$, $1.87(3 \mathrm{H}, \mathrm{brs}), 1.44(3 \mathrm{H}, \mathrm{s}), 1.40(3 \mathrm{H}, \mathrm{s}), 1.39(3 \mathrm{H}, \mathrm{s})$ and $1.16(3 \mathrm{H}, \mathrm{d}$, $J=6.8 \mathrm{~Hz})$.

\section{Preparation of 9-O-acetyl penicyrones A (1a) and B (2a)}

Acetic anhydride $(2.0 \mu \mathrm{l}, 21 \mathrm{nmol})$, pyridine $(2.0 \mu \mathrm{l}, 25 \mathrm{nmol})$ and 4 -(dimethylamino)pyridine $(0.1 \mathrm{mg}, 0.83 \mathrm{nmol})$ were added to a solution of compound $\mathbf{1}$ (2.0 mg, $4.6 \mathrm{nmol})$ in $\mathrm{CH}_{2} \mathrm{Cl}_{2}(100 \mu \mathrm{l})$, and the solution was stirred at room temperature for $10 \mathrm{~h}$. The reaction mixture was evaporated in vacuo, dissolved in water and extracted with EtOAc. The organic layer was concentrated in vacuo to give 9-O-acetyl-penicyrone A (1a, $1.66 \mathrm{mg}, 3.5 \mathrm{mmol}, 76.1 \%)$. The purity of the product was sufficient for NMR experiments.

9-O-Acetyl-penicyrone B (2a, $1.73 \mathrm{mg}, 3.6 \mathrm{mmol}, 78.3 \%$ ) was prepared by similar procedures as described above.

9-O-Acetyl-penicyrone A (1a): A colorless oil; $[\alpha]_{\mathrm{D}}^{21}+122\left(\right.$ c 0.10, $\left.\mathrm{CH}_{3} \mathrm{OH}\right)$; IR (KBr) $\nu_{\max } 3434,2973,2929,1739,1714,1690,1561,1454,1372,1355,1237$, 1089, 1043 and $1029 \mathrm{~cm}^{-1}$; UV $\left(\mathrm{CH}_{3} \mathrm{OH}\right) \lambda_{\max }(\mathrm{nm})(\log \varepsilon) 300$ (3.97); CD $\left(\mathrm{CH}_{3} \mathrm{OH}\right) \lambda_{\text {extermum }}(\mathrm{nm})(\Delta \varepsilon) 297(+10.9), 213(-33.5)$; HRFABMS $\mathrm{m} / \mathrm{z}$ $477.2492\left([\mathrm{M}+\mathrm{H}]^{+}\right.$; calcd for $\left.\mathrm{C}_{26} \mathrm{H}_{37} \mathrm{O}_{8}, 477.2488\right) ;{ }^{1} \mathrm{H}$ NMR $\left(\mathrm{CD}_{3} \mathrm{OD}\right): \delta 5.84$ $(1 \mathrm{H}, \mathrm{t}, J=0.9 \mathrm{~Hz}, \mathrm{H}-7), 5.65(1 \mathrm{H}, \mathrm{t}, J=0.9 \mathrm{~Hz}, \mathrm{H}-11), 5.32(1 \mathrm{H}, \mathrm{s}, \mathrm{H}-9), 4.02$ $(1 \mathrm{H}, \mathrm{q}, J=6.8 \mathrm{~Hz}, \mathrm{H}-15), 3.85$ (3H, s, H-18), 3.54 (1H, s, H-13), 2.08 (3H, s, H-19), 2.05 (3H, s, H-26), 2.02 (3H, s, H-17), 1.76 (3H, br d, $J=0.7 \mathrm{~Hz}, \mathrm{H}-22$ ), $1.61(3 \mathrm{H}, \mathrm{s}, \mathrm{H}-20), 1.41(3 \mathrm{H}, \mathrm{s}, \mathrm{H}-24), 1.39(3 \mathrm{H}, \mathrm{br} \mathrm{d}, J=1.0 \mathrm{~Hz}, \mathrm{H}-21), 1.30$ $(3 \mathrm{H}, \mathrm{s}, \mathrm{H}-23)$ and $1.11(3 \mathrm{H}, \mathrm{d}, J=6.8 \mathrm{~Hz}, \mathrm{H}-16)$.

9-O-Acetyl-penicyrone B (2a): A colorless oil; $[\alpha]_{\mathrm{D}}^{21}+118\left(c 0.10, \mathrm{CH}_{3} \mathrm{OH}\right)$; IR $(\mathrm{KBr}) \nu_{\max } 3432,2978,2934,1742,1714,1690,1561,1451,1372,1353,1235$, 1089, 1078, 1040 and $1026 \mathrm{~cm}^{-1}$; UV $\left(\mathrm{CH}_{3} \mathrm{OH}\right) \lambda_{\max }(\mathrm{nm})(\log \varepsilon) 297$ (3.85); $\mathrm{CD}\left(\mathrm{CH}_{3} \mathrm{OH}\right) \lambda_{\text {extermum }}(\mathrm{nm})(\Delta \varepsilon) 297(+13.8), 213(-41.2)$; HRFABMS $\mathrm{m} / z$ $477.2498\left([\mathrm{M}+\mathrm{H}]^{+}\right.$; calcd for $\left.\mathrm{C}_{26} \mathrm{H}_{37} \mathrm{O}_{8}, 477.2488\right) ;{ }^{1} \mathrm{H}$ NMR $\left(\mathrm{CD}_{3} \mathrm{OD}\right): 5.82$ $(1 \mathrm{H}, \mathrm{t}, J=0.9 \mathrm{~Hz}, \mathrm{H}-7), 5.67(1 \mathrm{H}, \mathrm{t}, J=0.9 \mathrm{~Hz}, \mathrm{H}-11), 5.30(1 \mathrm{H}, \mathrm{s}, \mathrm{H}-9), 4.02$ $(1 \mathrm{H}, \mathrm{q}, J=6.8 \mathrm{~Hz}, \mathrm{H}-15), 3.85(3 \mathrm{H}, \mathrm{s}, \mathrm{H}-18), 3.55(1 \mathrm{H}, \mathrm{s}, \mathrm{H}-13), 2.08(3 \mathrm{H}, \mathrm{s}$,
H-19), 2.024 (3H, s, H-26), $2.020(3 \mathrm{H}, \mathrm{s}, \mathrm{H}-17), 1.76(3 \mathrm{H}, \mathrm{br} \mathrm{d}, J=0.7 \mathrm{~Hz}$, $\mathrm{H}-22), 1.62(3 \mathrm{H}, \mathrm{s}, \mathrm{H}-20), 1.42$ (3H, s, H-24), $1.38(3 \mathrm{H}$, br d, $J=1.0 \mathrm{~Hz}, \mathrm{H}-21)$, $1.30(3 \mathrm{H}, \mathrm{s}, \mathrm{H}-23)$ and $1.11(3 \mathrm{H}, \mathrm{d}, J=6.8 \mathrm{~Hz}, \mathrm{H}-16)$.

\section{Conformational analysis}

The most stable conformers of 1a and 2a were predicted using Spartan' 14 (Wavefunction, Irvine, CA, USA) by a preliminary conformational analysis with the MMFF94 force field followed by geometry optimization using the density functional theory with the B3LYP functional and 6-31G* basis set.

\section{Anti-microbial assay}

An anti-bacterial assay was carried out using M. smegmatis NBRC 3207 by the paper disc method. ${ }^{25,26}$ Strain NBRC 3207 was obtained from the Biological Resource Center (NBRC) and NITE (Chiba, Japan), and maintained in $20 \%$ glycerol at $-80^{\circ} \mathrm{C}$.

The test microorganism was cultured in Middlebook $7 \mathrm{H} 9$ broth containing $0.05 \%$ polysorbate $80,0.5 \%$ glycerol and $10 \%$ Middlebook OADC at $37{ }^{\circ} \mathrm{C}$ for 2 days and adjusted to $1.0 \times 10^{6} \mathrm{CFU} \mathrm{ml}^{-1}$. The inoculum was spread on the above medium containing $1.5 \%$ agar in a square plate. Each sample in $\mathrm{CH}_{3} \mathrm{OH}$ was adsorbed to a sterile filter disc ( $6 \mathrm{~mm}$; Advantec, Tokyo, Japan), and, after the evaporation of $\mathrm{CH}_{3} \mathrm{OH}$, the disc was placed on an agar plate and incubated for 2 days at $37^{\circ} \mathrm{C}$. Streptomycin sulfate and $\mathrm{CH}_{3} \mathrm{OH}$ were used as positive and negative controls, respectively.

\section{CONFLICT OF INTEREST}

The authors declare no conflict of interest.

\section{ACKNOWLEDGEMENTS}

This work was supported in part by a Grant-in-Aid for Scientific Research (25870660) from the Ministry of Education, Culture, Sports, Science and Technology (MEXT) of Japan (to HY) and by the Foundation for Japanese Chemical Research (to HY). We express our thanks to Mr T Matsuki and $S$ Sato of Tohoku Pharmaceutical University for measuring mass and NMR spectra and to the fishermen of the Oshika Peninsula, Miyagi Prefecture, Japan, for collecting the samples.

1 Blunt, J. W., Copp, B. R., Keyzers, R. A., Munro, M. H. \& Prinsep, M. R. Marine natural products. Nat. Prod. Rep. 32, 116-211 (2015); previous reports in this series.

2 Faulkner, D. J. Marine natural products. Nat. Prod. Rep. 19, 1-48 (2002); previous reports in this series.

3 Skropeta, D. \& Wei, L. Recent advances in deep-sea natural products. Nat. Prod. Rep. 31, 999-1025 (2014).

4 Bhatnaga, I. \& Kim, S. K. Immense essence of excellence: marine microbial bioactive compounds. Mar. Drugs 8, 2673-2701 (2010).

5 Bugni, T. S. \& Ireland, C. M. Marine-derived fungi: a chemically and biologically diverse group of microorganisms. Nat. Prod. Rep. 21, 143-163 (2004).

6 Jensen, P. R. \& Fenical, W. in Drugs from the Sea. Marine Microorganisms and Drug Discovery: Current Status and Future Potential (ed. Fusetani, N.) 6-29 (Karger, Basel, 2000).

7 Wilson, B. J., Byerly, C. S. \& Burka, L. T. Neurologic disease of fungal origin in three herds of cattle. J. Am. Vet. Med. Assoc. 179, 480-481 (1981).

8 Burka, L. T., Ganguli, M. \& Wilson, B. J. Verrucosidin, a tremorgen from Penicillium verrucosum var. cyclopium. J. Chem. Soc. Chem. Commun. 544-545 (1983).

9 Hodge, R. P., Harris, C. M. \& Harris, T. M. Verrucofortine, a major metabolite of Penicillium verrucosum var. Cyclopium, the fungus that produces the mycotoxin verrucosidin. J. Nat. Prod. 51, 66-73 (1988).

$10 \mathrm{Yu}, \mathrm{K}$. et al. Verrucosidinol and verrucosidinol acetate, two pyrone-type polyketides isolated from a marine derived fungus Penicillum aurantiogriseum. Mar. Drugs $\mathbf{8}$, 2744-2754 (2010).

11 Choo, S. J. et al. Deoxyverrucosidin, a novel GRP78/Bip down-regulator, produced by Penicillium sp. J. Antibiot. 58, 3, 210-213 (2005).

12 Arai, K., Kimura, K., Mushiroda, T. \& Yamamoto, Y. Structures of fructigenines A and B, new alkaloids isolated from Penicillium fructigenum TAKEUCHI. Chem. Pharm. Bull. 37, 2937-2939 (1989).

13 Kozlovsky, A. G., Adanin, V. M., Dahse, H. M. \& Grafe, U. Rugulosuvines A and B, diketopiperazine alkaloids of Penicillium rugulosum and Penicillium piscarium fungi. Appl. Biochem. Microbiol. 37, 253-256 (2001).

14 Kimura, Y. et al. Cyclo-(L-tryptophyl-L-phenylalanyl), a plant growth regulator produced by the fungus Penicillium sp. Phytochemistry 41, 665-669 (1996). 
$15 \mathrm{Chu}$, D. et al. Biological active metabolite cyclo (L-Trp-L-Phe) produced by South China Sea sponge Holoxea sp. associated fungus Aspergillus versicolor strain TS08. Bioprocess Biosyst. Eng. 34, 223-229 (2011).

16 Birkinshaw, J. H., Luckner, M., Mohammed, Y. S., Mothes, K. \& Stickings, C. E. Studies in the biochemistry of micro-organisms. 114. Viridicatol and cyclopenol, metabolites of Penicillium viridicatum Westling and Penicillium cyclopium Westling. Biochem. J. 89, 196-202 (1963).

17 Bracken, A., Pocker, A. \& Raistrick, H. Studies in the biochemistry of micro-organisms 93. Cyclopenin, a nitrogen-containing metabolic product of Penicillium cyclopium Westling. Biochem. J. 57, 587-595 (1954).

18 Nakahara, S., Kusano, M., Fujioka, S., Shimada, A. \& Kimura, Y. Penipratynolene, a novel nematicide from Penicillium bilaiae Chalabuda. Biosci. Biotechnol. Biochem. 68, 257-259 (2004).

19 Jian, Y. J. \& Wu, Y. K. On the structure of penipratynolene and WA. Terahedron 66 , 637-640 (2010).

20 Shimada, A. et al. Aspterric acid and 6-hydroxymellein, inhibitors of pollen development in Arabidopsis thaliana, produced by Aspergillus terreus. J. Biosci. 57, 459-464 (2002).
21 Yurchenko, A. N. et al. A new meroterpenoid from the marine fungus Aspergillus versicolor (Vuill.) Tirab. Russ. Chem. Bull. Int. Ed. 59, 852-856 (2010).

22 Cha, J. K. \& Cooke, R. J. Synthetic studies toward verrucosidin: determination of the absolute configuration. Tetrahedron Lett. 28, 5473-5476 (1987).

23 Hatakeyama, S., Sakurai, K., Numata, H., Ochi, N. \& Takano, S. A novel chiral route to substituted tetrahydrofurans. Total synthesis of (+)-verrucosidin and formal synthesis of (-)-citreoviridin. J. Am. Chem. Soc. 110, 5201-5203 (1988).

24 Whang, K., Cooke, R. J., Okay, G. \& Cha, J. K. Total synthesis of (+)-verrucosidin. J. Am. Chem. Soc. 112, 8989-8987 (1990).

25 Ericsson, H. The paper disc method for determination of bacterial sensitivity to antibiotics. Studies on the accuracy of the technique. Scand. J. Clin. Lab. Invest. 12, 408-413 (1960).

26 Bu, Y.-Y., Yamazaki, H., Ukai, K. \& Namikoshi, M. Anti-mycobacterial nucleoside antibiotics from a marine-derived Streptomyces sp. TPU1236A. Mar. Drugs 12 6102-6112 (2014). 